\title{
Interstimulus interval functions in different response systems during classical discrimination conditioning of rabbits '
}

\author{
D. H. VANDERCAR AND N. SCHNEIDERMAN \\ UNIVERSITY OF MLAMI
}

Each of four groups of rabbits received nictitating membrane (NM), heart rate (HR) and respiration rate $(R R)$ classical discrimination conditioning to tones and shocks at interstimulus intervals of $.25, .75,2.25$ and $6.75 \mathrm{sec}$. Percentages of NM CRs were inversely related to ISI; whereas magnitude of $R R$ responding was directly related to $I S I$, and maximum $H R$ conditioning occurred at $2.25 \mathrm{sec}$. Discrimination conditioning failed to occur in acquisition in the $R R$ response system, and occurred maximally at $.75 \mathrm{sec}$ in the NM system and $2.25 \mathrm{sec}$ in the HR system.

It is generally recognized that interstimulus interval (ISI) is an important determiner of performance in classical conditioning, and equally well known that divergent ISI functions occur among different response systems. The relationships between response systems and ISI functions, however, have not been satisfactorily explained. Jones (1962), for example, attempted to account for the divergences in ISI functions among response systems on the basis of differences in response latencies. Schneiderman, Smith, Smith, \& Gormezano (1966) however, have observed that although HR conditions at longer ISIs than those reported for NM responses in the rabbit, both NM and HR responses reveal short latencies when conditioned at an ISI as short as $2 \mathrm{sec}$.

In the present experiment, the hypothesis was investigated that the extent to which conditioning occurs in a particular response system is a function of the degree to which the ISI and CR duration of the response system favor CR-US overlap. Thus, a short (NM) and two long (RR and HR) CR duration response systems were jointly and simultaneously conditioned in rabbits at several ISIs.

Method

Each of 32 Ss was assigned to one of four groups which received classical discrimination training at ISIs of .25, .75, 2.25, and 6.75 sec under a delay procedure in which CS offset was coincident with US onset. All Ss received one day of adaptation to 550 and 3400 cps tones at $78 \mathrm{~dB} \mathrm{SPL}$, followed by seven days of classical discrimination conditioning and three days of experimental extinction to both tones. In each acquisition session the $S$ received 80 trials at an intertrial interval of $90 \mathrm{sec}$. Thirty-five presentations of one frequency tone were followed by a $5 \mathrm{~mA}$ ac shock to the lateral canthus of the right eye, and five presentations of the same frequency tone presented alone served as test trials for the reinforced tone. Of the 40 pre- sentations of the never reinforced tones, five presentations served as test trials.

The conditioning apparatus, methods of NM and HR recording, and manner in which each $\mathrm{S}$ was restrained with a Plexiglas box have previously been described (Schneiderman \& Gormezano, 1964; Schneiderman et al, 1966). Respiration rate was recorded by means of a thermocouple inserted into a hole at the distal end of a small rubber mask fastened over the end of the S's snout and was amplified by a Grass Model 111D EEG machine.

Measures of $\mathrm{HR}$ (and RR) were obtained on test trials by dividing the duration in time of the 25 successive heart beats (or four successive $\mathrm{RR}$ cycles) occurring after tone onset by the duration of the 25 heart beats (or four RR cycles) preceding tone onset; frequencies of NM responses were also recorded on test trials. In addition the topography of the HR response was analyzed by: (a) measuring the duration of two successive groups of five beats immediately prior to CS onset, (b) deriving the mean five beat duration from this as a baseline score, and (c) dividing the duration of each of the five successive groups of five beats occurring after CS onset by the baseline score. Finally, frequency measures of HR responding were computed by defining a CR on each test trial as a change from baseline exceeding either $0,1,2,3,4$, or 5 percent. Separate analyses of variance in conjunction with Duncan range tests of pairwise comparisons were conducted upon $N M, H R$, and RR cumulative response totals; the confidence level utilized for all tests was $p<.05$.

Results

Figure 1 shows the percentage of conditioned NM responses for each group during acquisition and extinction. In acquisition the level of responding to the CS was inversely related to ISI with little or no conditioning occurring at the longest interval. Statistical analyses of NM responses cumulated over the seven days of acquisition confirmed the findings that in the NM system: (a) the highest level of responding to the CS+ occurred in the .25 sec ISI group; (b) the greatest amount of differential responding occurred in the .75 sec group; and (c) differential conditioning occurred in all but the 6.75 sec group. Similar analyses conducted upon NM responses cumulated over all extinction trials confirmed the findings that differential conditioning occurred in the two shortest ISI groups, but not in the 2.25 or $6.75 \mathrm{sec}$ groups. 
An analysis of the topography of the HR responses to the CS+ during acquisition and the first extinction session Indicated that the HR CR was a decrease in rate, and that the maximum percentage change from baseline in the $.25, .75$, and 2.25 sec ISI groups occurred within the first 10 beats after CS onset. In contrast, the maximum percent changes from baseline in the $6.75 \mathrm{sec}$ ISI group occurred during the fourth and fifth five beat intervals which occurred from 5.6 to $7.0 \mathrm{sec}$ after CS onset.

In contrast to the decreasing levels of NM responding with increasing ISI and absence of discrimination at $6.75 \mathrm{sec}$, the statistical analyses conducted upon magnitude of HR responses cumulated over test trials in acquisition (see Fig. 2) indicated that in the HR system: (a) the highest level of responding to the CS+ occurred at an ISI of $2.25 \mathrm{sec}$ (b) all ISI groups revealed reliable differential conditioning; and (c) the greatest amount of differential conditioning occurred at the $2.25 \mathrm{sec}$ ISI. The same results were also obtained when the statistical analyses were performed upon percent CR measures of HR conditioning using criteria of 3,4 , or 5 percent changes from baseline to define a CR. In extinction, the 2.25 and $6.75 \mathrm{sec}$ ISI groups revealed reliably higher levels of responding than the shorter ISI groups. Although no group demonstrated reliable RR differential conditioning in acquisition, the 2.25 and $6.75 \mathrm{sec}$ ISI groups discriminated reliably in extinction. Statistical analyses Indicated that $\mathbf{2 . 2 5}$ and $6.74 \mathrm{sec}$ ISI groups significantly differed from the .25 and .75 sec ISI groups in amount of RR discrimination in extinction.

\section{Discussion}

The present findings of differences among response systems in ISI function is consistent with the time discrimination hypothesis described by Ebel \& Prokasy (1963). According to this hypothesis, strength of con-

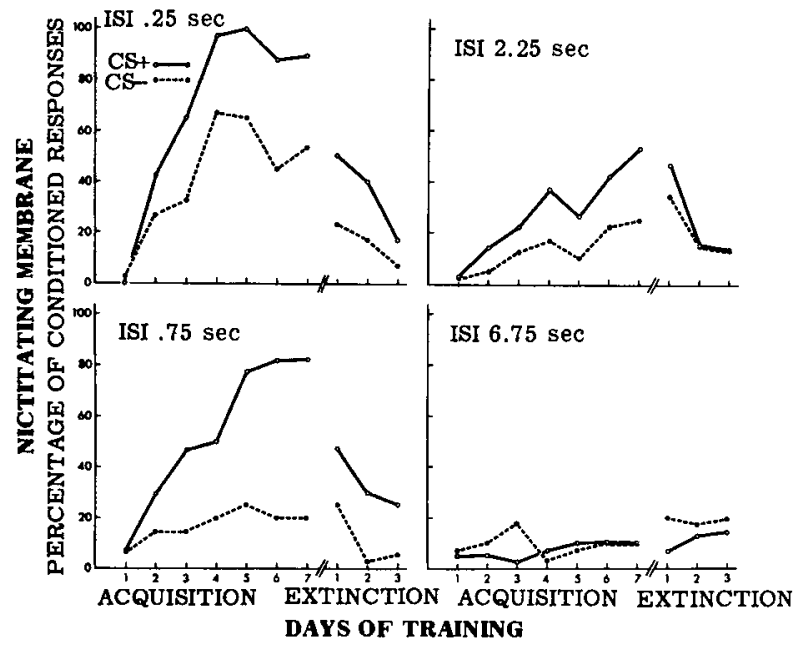

Fig. 1. Percentages of nictitating membrane responses to CS+ and CSteat trials for each ISI group during acquisition and extinction.

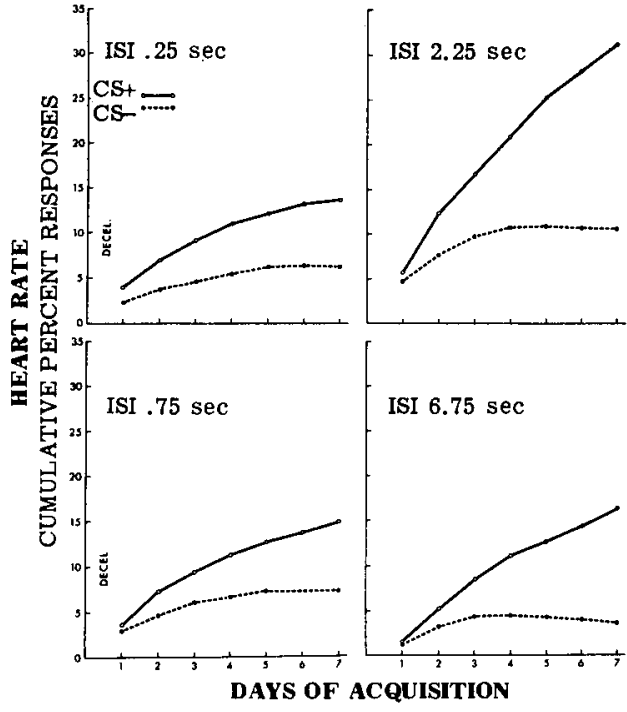

Fig. 2. Mean percent decreases of heart rate from baseline on test trials cumulated over acquisition sessions.

ditioning is related to the extent to which a particular ISI favors $S$ making a time discrimination which allows kinesthetic feedback from $\mathrm{CR}$ to occur in proximity with a US. Since duration of a CR would thus appear to be directly related to the probability of overlap occurring, we should predict that a response system such as HR or RR which produces long duration CRs would reveal more rapid conditioning across a greater range of ISIs than a response system such as NM which produces short duration CRs.

In the present experiment the $\mathrm{NM}$ response system failed to reveal any conditioning at $6.75 \mathrm{sec}$, whereas the $H R$ and $R R$ response systems revealed conditioning at this interval. The finding that the HR response revealed a maximum level of conditioning at $2.25 \mathrm{sec}$ and lesser levels at ISIs of .25 and .75 sec may have been related to the $S^{\prime}$ 's inability to execute CRs at short intervals because of response truncation by the US. A similar explanation would also hold in the RR response system for the direct relationship between conditioning level and ISI.

\section{References}

EBEL, H. C., \& PROKASY, W. F. Classical eyelid conditioning as a function of sustained and shifted interstimulus intervals. $J$. exp. Psychol, 1963, 65, 52-58.

JONES, J. E. Contiguity and reinforcement in relation to CS-UCS intervals in classical aversive conditioning. Psychol. Rev., 1962, 69, 176186.

SCHNEIDERMAN, N., \& GORMEZANO, I. Conditioning of the nictitating membrane of the rabbit as a function of CS-US interval. $J$. comp. physiol Psychol, 1964, 188-195.

SCHNEIDERMAN, N., SMITH, M. C., SMITH, A., \& GORMEZANO, I. Heart rate classical conditioning in rabbits. Psychon Sci, 1966, 6, 241-242.

Note

1. Supported by NSF grant GB-5307. 